\title{
Artificial Intelligence (AI) techniques to analyze the determinants attributes in housing prices
}

\section{Técnicas de Inteligencia Artificial (IA) para analizar los atributos determinantes en el precio de una vivienda}

\author{
Julia M. Núñez Tabales, Francisco J. Rey Carmona y José Ma Caridad y Ocerin \\ Facultad de Derecho y Ciencias Económicas y Empresariales. Universidad de Córdoba. Puerta \\ Nueva s/n. 14071. Córdoba (España). \\ int@uco.es
}

\begin{abstract}
The econometric approach to obtain the value of a property began with hedonic modelling, which were based on a set of property attributes, internal or external, associated to each particular dwelling. The final sale value can be estimated, and also the marginal prices of each exogenous explanatory variable. A good alternative to the hedonic approach is based on several Artificial Intelligence (AI) techniques, such as artificial neural networks (ANN), these tend to be more precise. Both methodologies are compared, and a case study is developed using data from Seville, the larger town in the South of Spain.

Resumen El análisis abordado tiene como objetivo la obtención de modelos econométricos de valoración de vivienda. Partiendo de una serie de atributos referidos al inmueble -internos y externos- se pretende obtener el precio de venta del mismo, estimando además el peso marginal de cada uno de los atributos que explican el precio global. Debido al carácter heterogéneo de estos bienes se utiliza desde hace varias décadas la Metodología de Precios Hedónicos. Sin embargo, las técnicas de Inteligencia Artificial (IA), en especial las Redes Neuronales Artificiales (RNA) suelen ser más precisas en este ámbito. Se efectuó una comparativa entre ambas técnicas en la ciudad de mayor tamaño del sur de España: Sevilla.
\end{abstract}

Keywords: House prices, Artificial Neural Networks (ANN), Valuation, Hedonic Prices Methodology (HPM). Palabras clave: Precios de la vivienda, Redes Neuronales Artificiales (RNA), Valoración, Metodología de Precios Hedónicos (MPH).

\section{Introduction}

La determinación y análisis de los precios de los inmuebles posee un interés particular por la implicación del sector de la construcción en el devenir económico de una región.

Por lo que respecta al concepto de valoración inmobiliaria, son muchas las definiciones de que se pueden encontrar en la literatura especializada. Para García Almirall (2007) [1] la valoración inmobiliaria trata de discernir el valor de una determinada propiedad, constituida generalmente por suelo, edificación o inmueble (suelo y edificio). Ballestero y Rodríguez (1999) [2] consideran que "en su aspecto de ciencia aplicada, la valoración proporciona criterios para estimar valores, cuando los precios no son transparentes". Por su parte, Llano (2007) [3], propone la siguiente definición: "La valoración inmobiliaria consiste en determinar el valor de mercado de un bien inmueble expresado en unidades monetarias, en un momento determinado y con una finalidad concreta". 
En nuestros días, la valoración inmobiliaria emerge como actividad pluridisciplinar en la que se combinan diferentes técnicas y metodologías de estudio con objeto de establecer el valor real de un producto inmobiliario.

Por consiguiente, la temática abordada en este trabajo puede ser de interés para muy diversos colectivos, entre los que podrían citarse ciudadanos inmersos en procesos de valoración inmobiliaria (adquisiciones de viviendas, solicitudes de préstamos hipotecarios, herencias, inversiones en inmuebles, etc.), agentes de la propiedad inmobiliaria, Administraciones Públicas -dado que una parte importante de la recaudación tributaria tiene su origen en el gravamen de bienes inmuebles- y empresas de cualquier ámbito económico -en especial las pertenecientes al sector financiero, entidades aseguradoras y fondos de inversión inmobiliaria- ${ }^{1}$.

Dentro del mercado inmobiliario el mercado de la vivienda es el principal componente, hasta el punto de que con relativa frecuencia se utilizan ambos términos indistintamente.

Existe abundante literatura científica de valoración inmobiliaria, pero muy pocos son los estudios que se detienen en determinar los precios de los atributos relevantes en el montante total del inmueble. Por tanto, resulta de interés conocer, en primer lugar, cuáles son las distintas metodologías alternativas disponibles para la valoración de inmuebles urbanos y, en segundo lugar, cuáles son los atributos determinantes del precio de una vivienda, estimando el peso marginal de cada atributo de modo que se consiga valorar su importancia relativa sobre el precio total del inmueble.

En el apartado empírico se obtienen diferentes modelos predictivos del precio de una vivienda en la ciudad de Sevilla, utilizando técnicas de Inteligencia Artificial (IA) - concretamente Redes Neuronales Artificiciales (RNA)y metodología hedónica clásica. Posteriormente, se realizará un análisis comparativo de los resultados obtenidos por ambas metodologías con objeto de determinar aquella que ofrece mejores resultados.

\section{Metodologías para la determinación de precios inmobiliarios}

Varios han sido los autores que han intentado efectuar una clasificación de la diversidad de métodos existentes para la valoración de un inmueble. Entre las propuestas que gozan de mayor aceptación destaca la realizada por Pagourtzi et al. (2003) [5], que clasifica los métodos en dos categorías: métodos tradicionales y métodos avanzados. Los primeros coinciden básicamente con los métodos técnicos de valoración. Entre los métodos avanzados incluye las RNA, el método de precios hedónicos, los métodos de análisis espacial, la lógica difusa y las técnicas Box-Jenkins -Autoregressive Integrated Moving Average (ARIMA)-.

Por otra parte, conviene señalar las clasificaciones metodológicas efectuadas por Gallego (2008) [6] y Aznar (2012) [7]. El primero también realiza una distinción entre los métodos de valoración tradicionales y los métodos de valoración automatizada. Dentro del primer grupo se incluyen aquellos basados fundamentalmente en el criterio de un experto, cuentan con un alto grado de precisión, pero se caracterizan por su elevado nivel de subjetividad y por una baja producción en cuanto al número de valoraciones. En un segundo grupo encuadra a los que denomina métodos de valoración automatizada ${ }^{2}$, caracterizados fundamentalmente por el empleo de técnicas matemáticas para la estimación del valor. Entre los procedimientos más utilizados para modelizar el valor mercado relaciona a las regresiones, a las RNA y al método K-Vecinos.

Aznar (2012) [7] plantea una clasificación de los métodos de valoración realizada a partir de los recogidos en las Normas Internacionales de Valoración, a los que añade los denominados métodos multicriterio, así como distintos métodos previstos para la valoración de activos y recursos ambientales. Establece cinco grupos distintos bajo las siguientes denominaciones: comparativos, actualización, mixtos, coste y valoración ambiental. Ahora bien, este último grupo no es utilizado en la valoración de inmuebles urbanos -como su propia denominación sugiere-. El autor considera que los más frecuentemente utilizados en la práctica son los métodos por corrección (en sus dos variantes: simple y múltiple), el método del ratio de valoración, el método Beta, el método del análisis de regresión, el método de actualización de rentas, el método del coste de reemplazamiento y el del valor residual.

En un intento de aunar las posibles clasificaciones, se van a diferenciar dos grupos entre los distintos métodos de valoración de inmuebles: métodos técnicos ${ }^{3}$ y métodos avanzados (véase Tabla 1).

\footnotetext{
${ }^{1}$ Para evidenciar la importancia de la valoración inmobiliaria puede mostrarse como dato que en España, a lo largo del año 2013, las 52 sociedades de tasación homologadas efectuaron un total de 661.000 tasaciones (59\% correspondían a vivienda), con un valor total tasado que ascendió a 265 mil millones de euros y una superficie total de los bienes inmuebles valorados en el ejercicio de 517.000 hectáreas (Boletín Económico del Banco de España, julio-agosto de 2014) [4].

${ }^{2}$ El propio autor precisa que esta denominación no obedece a la utilización de técnicas informáticas, puesto que también son empleadas en los métodos tradicionales.

${ }^{3}$ Desarrollados con detalle por Ferrando (2011) [8].
} 
Tabla 1: Clasificación de los métodos de valoración de inmuebles.

\begin{tabular}{|c|c|}
\hline GRUPO & MÉtodo \\
\hline TÉCNICOS & $\begin{array}{l}\text { Coste } \\
\text { Comparación con el mercado } \\
\text { Actualización de rentas } \\
\text { Residual } \\
\text { - } \quad \text { Dinámico } \\
\text { - } \quad \text { Estático }\end{array}$ \\
\hline AvANZADOS & $\begin{array}{l}\text { Inteligencia Artificial (RNA, Lógica difusa, Sistemas Expertos, Algoritmos Genéticos -AG-) } \\
\text { Precios Hedónicos } \\
\text { Análisis Espacial } \\
\text { K-Vecinos } \\
\text { Técnicas Box-Jenkins (ARIMA) } \\
\text { Basados en la Teoría de decisión multicriterio (CRITIC, entropía, ordenación simple, } \\
\text { proceso analítico en red -ANP-, Programación por metas -PG-, Multicriteria Valuation } \\
\text { Method-MAVAM-) }\end{array}$ \\
\hline
\end{tabular}

Fuente: Elaboración propia

Dentro del segundo grupo se efectuará a continuación una especial referencia a las técnicas aplicadas en el apartado empírico de este trabajo (RNA y Metodología de Precios Hedónicos -MPH-), incluyendo las más destacadas aportaciones efectuadas en el campo de la valoración de inmuebles.

\subsection{Metodología de Precios Hedónicos (MPH)}

Siguiendo un orden cronológico, en primer lugar aparece la MPH que tiene su fundamento en el hecho de que algunos bienes no son homogéneos, diferenciándose en función de numerosas características, por lo que se presentan en el mercado en forma de conjuntos de atributos variables. Los bienes inmuebles pueden ser considerados como el prototipo de bienes que son transmitidos como un conjunto de atributos ligados a la unidad física que se transmite (Figueroa et al., 1992) [9]. Asimismo, los bienes inmuebles poseen una gran variedad de atributos físicos, funcionales, de localización, etc., que los hacen prácticamente únicos e irrepetibles. Pero dado que lo que se ofrece es el bien en su conjunto no resulta posible observar los precios de los atributos que lo componen. Mediante su propio juego de oferta y demanda cada uno de esos atributos, son valorados a sus respectivos precios implícitos determinando el precio final del bien transmitido.

No existe en la literatura unanimidad en relación con el origen en la utilización de los precios hedónicos. Para Goodman (1995) [10], Andrew Court [11] fue el que usó, en un artículo del año 1939, por primera vez el término hedónico, para la determinación del precio de vehículos. Para otros autores, como Colwell y Dilmore (1999) [12], la primera aplicación de los modelos hedónicos fue la realizada por Haas (1922) [13], en el marco de un estudio sobre los precios de explotaciones de naturaleza agrícola.

Ridker y Henning (1967) [14] fueron los primeros en utilizar la metodología de precios hedónicos en el mercado de la vivienda, en su estudio sobre la incidencia de la polución y las características del vecindario en el precio de la vivienda en San Luis (Estados Unidos). En general existe consenso en considerar que fueron los trabajos de Griliches (1971) [15] y Rosen (1974) [16] los que difundieron la aplicación de este método. Concretamente es este último quien propone las bases teóricas del equilibrio del mercado tanto desde el punto de vista del consumidor como del oferente. Así, el bien es definido por $n$ atributos o características, que se pueden representar a través de un vector de coordenadas:

$$
\mathrm{Z}=\left(\mathrm{z}_{1}, \mathrm{z}_{2}, \ldots, \mathrm{z}_{\mathrm{n}}\right) .
$$

Por tanto, la función de precios hedónica para cualquier bien heterogéneo, $\mathrm{p}(\mathrm{z})$, determina un equilibrio entre las valoraciones, de consumidores (para un nivel de utilidad determinado $\mathrm{u}_{\mathrm{i}}$ ) y de productores (para un nivel de beneficio $\pi_{i}$ ), de las características que incorpora ese bien.

Por su parte, Freeman (1979) [17] proporcionó la que se considera por muchos autores primera justificación teórica para la aplicación de esta metodología al mercado de la vivienda.

Sin embargo, el modelo no está exento de limitaciones entre las que cabe destacar la relativa a la posible presencia de multicolinealidad o de heterocedasticidad entre las variables explicativas, así como las imperfecciones del mercado y la información incompleta. Además, esta metodología también tiene como punto de partida el hecho de que los consumidores están en condiciones de percibir las diferencias en los atributos, puesto que de otro modo el precio final no las reflejaría. 
Entre los estudios recopilatorios de las variables explicativas o exógenas del modelo de valoración más usadas en la literatura destaca el de Sirmans et al. (2005) [18] que afirma que la edad del inmueble es la variable más frecuentemente encontrada, seguida de la superficie, la presencia de garaje, el número de dormitorios, el número de baños, la presencia de piscina o de sótano, la ubicación geográfica (medida por barrio, vecindario o código postal) y el ambiente natural (buenas vistas), etc.

Las primeras aplicaciones de MPH a la valoración inmobiliaria en España se remontan al año 1984 con los trabajos de Peña y Ruiz-Castillo [19] en la Comunidad Autónoma de Madrid. Hubo que esperar más de una década para encontrar la siguiente aportación en España, Brañas y Caridad (1996) [20] en la ciudad de Córdoba. En la primera década del siglo XXI han proliferado los estudios, pudiendo destacarse las aportaciones de BilBao Terol (2000) [21] en Asturias, Bover y Velilla (2001) [22] en Madrid, García Pozo (2007) [23] en Málaga, Fitch y García Almirall (2008) [24] en Barcelona y Chasco y Le Gallo (2013) [25] en Madrid.

\subsection{Redes Neuronales Artificiales (RNA)}

Las RNA pertenecen al campo de la Inteligencia Artificial (IA), entendida esta como un conjunto de algoritmos cuyo objetivo es imitar el razonamiento humano a través de una lógica deductiva o manipulación de símbolos (Martín y Sanz, 2006) [26].

Asimismo, dentro de la IA se pueden distinguir dos grandes áreas (Isasi y Galván, 2004) [27], una es la de la IA simbólica, la que se ocupa de la construcción de sistemas que se puedan definir como "inteligentes". La otra gran área de la IA es la subsimbólica, es el caso en que no se realizan diseños a alto nivel de sistemas capaces de resolver los problemas utilizando las técnicas de la disciplina, sino que se parte de sistemas genéricos que van adaptándose y construyéndose hasta formar por sí mismos un sistema capaz de resolver el problema. Es en esta área donde se ubican las RNA. Quedarían vinculadas al ámbito de la IA técnicas como la Lógica Difusa o Borrosa (Fuzzy Logic), los Sistemas Expertos, los Algoritmos Genéticos y las ya mencionadas RNA.

Una Red Neuronal Artificial -también denominada neuro-computadora, red conexionista o procesador paralelo distribuido (Sánchez y Alanís, 2006) [28]- es un procesador paralelo distribuido y masivamente interconectado que almacena conocimiento experimental (Haykin, 1999) [29].

La mayoría de los autores coinciden en citar los estudios de Warren McCulloch y Walter Pitts (1943) [30] como los primeros con relevancia en el ámbito de las redes, dado que formulan el primer modelo matemático básico de una neurona artificial, basado en la idea de que las neuronas operan mediante impulsos binarios. No obstante, la principal aportación, ya en la década de los 50, es la de Frank Rosenblatt (1958) [31], quien generalizó el modelo primitivo propuesto por McCulloch y Pitts añadiéndole aprendizaje y denominando a este nuevo modelo Perceptron. Las limitaciones de este modelo primitivo fueron solventadas décadas más tarde por Rumelhart et al. (1986) [32] mediante el desarrollo del algoritmo de aprendizaje de retropropagación (backpropagation o BP) para perceptrón multicapa (Multi Layer Perceptron -MLP-).

La unidad básica de una RNA es la neurona artificial (nodo o elemento de proceso), que tiene un valor de activación y se compone de:

a) Vector de entradas (inputs): $\boldsymbol{x}^{\prime}=\left(x_{1}, x_{2}, \ldots x_{i}, \ldots x_{n}\right) € \mathrm{R}^{\mathrm{n}}$, con $x_{i} € \mathrm{R}$ o $x_{i} €\{0,1\}$, es decir, es una medida continua o binaria.

b) Vector de pesos sinápticos: $\omega=\left(\omega_{1}, \omega_{2}, \ldots, \omega_{i}, \ldots, \omega_{n}\right) € \mathrm{R}^{\mathrm{n}}$.

c) Regla de propagación: en general, la suma ponderada o producto escalar $\boldsymbol{\omega} \cdot \boldsymbol{x}$.

d) Función de activación o de transferencia: $g$, que proporciona el valor de salida $y$.

e) Valor de salida (output): $y € \mathrm{R}, y €\{0,1\}, y €\{-1,1\}, y €[0,1]$ o $y €[-1,1]$

La neurona recibe $n$ entradas o inputs $\left(x_{i}\right)$, cada una de ellas a través de una conexión de entrada a la que se asocia un peso $\left(\omega_{i}\right)$. Los pesos, en valor absoluto, miden la fuerza o intensidad de la conexión, mientras que el signo permite distinguir el carácter de la misma. Es preciso incluir una regla de aprendizaje, procedimiento por el cual se procede a la modificación del patrón de conexión -pesos o ponderaciones sinápticas-, de forma que los pesos se irán actualizando permitiendo así aprender a la red.

Así pues, una RNA consta de varios elementos de proceso, conectados de alguna forma, generalmente organizados en grupos que se denominan capas. Existen dos capas típicas en toda red, que contienen conexiones con el exterior: La capa de entrada, a través de la cual se presentan los datos a la red y la capa de salida, que muestra la respuesta de la red a una entrada. 
En la valoración de inmuebles el Perceptrón Multicapa -Multi Layer Preceptron (MLP)- es el más usado, aunque también se han encontrado referencias en las que se aplican otro tipo de modelos como la Función de Base Radial -Radial Basis Function (RBF)- (García Rubio, 2004) [33] y los Mapas Auto-organizativos de KohonenSelf-Organization Maps (SOM)- (Kauko, 2009 [34]; Kontrinas y Verikas, 2011 [35]).

Las RNA ofrecen ventajas que justifican su creciente interés con respecto a otras metodologías (Soria y Blanco, 2001 [36]; Gallego, 2004 [37]) como su elevada potencia computacional, ser sistemas tolerantes a fallos, establecer relaciones no lineales entre datos y su capacidad de adaptabilidad.

Los primeros estudios sobre valoración de inmuebles que utilizan la IA a nivel internacional datan de principios de los años 90 (Borst, 1991 [38] y Tay y Ho, 1992 [39]). La mayor parte de los sistemas de IA aplicados a este campo son RNA. La primera aportación a este campo en España tienen algo más de una década (Caridad y Ceular, 2001 [40]) y fue efectuada en la ciudad de Córdoba. Posteriormente destaca, por ejemplo, el análisis pormenorizado realizado por Gallego (2004) [35] en la capital de España o los realizados en Albacete (García Rubio, 2004 [31]), Jaén (Lara Cabeza, 2005 [41]) y Oviedo (Landajo et al., 2012 [42]). Sin embargo, no existen precedentes para la capital andaluza -Sevilla-, siendo éste uno de los motivos para la consideración de este enclave en el apartado empírico de esta tesis.

En la capa de entrada (inputs) del MLP se sitúan las variables que se consideran determinantes del precio del inmueble. En cuanto a la capa de salida de la red (output), ésta estará constituida por un único nodo o neurona que suele ser el precio de venta del inmueble (ya sea total o por metro cuadrado).

\section{Estudio Empírico}

\subsection{Información disponible}

Para la realización del estudio de valoración de vivienda que se pretende es necesario disponer simultáneamente de precios de venta de inmuebles y de las características o atributos que poseen dichos inmuebles.

Tabla 2: Clasificación de atributos del inmueble.

\begin{tabular}{|c|c|c|c|}
\hline \multicolumn{2}{|r|}{ INTERNAS } & \multicolumn{2}{|c|}{ EXTERNAS } \\
\hline BÁSICAS & $\begin{array}{l}\text { SUPERFICIE } \\
\text { DORMITORIOS } \\
\text { BAÑOS } \\
\text { SALONES } \\
\text { PLANTA }\end{array}$ & \multirow[t]{2}{*}{ GENERALES } & \multirow[t]{2}{*}{$\operatorname{ASCENSOR}(*)$} \\
\hline \multirow{3}{*}{ EXTRAS } & \multirow{3}{*}{$\begin{array}{l}\text { COCINA AMUEBLADA }(*) \\
\text { REFORMADO }(*) \\
\text { ORIENTACIÓN EXTERIOR }(*) \\
\text { TERRAZA }(*) \\
\text { ARMARIOS EMPOTRADOS }(*) \\
\text { CHIMENEA }(*) \\
\text { VESTIDOR }(*) \\
\text { COCHERA }(*) \\
\text { TRASTERO }(*) \\
\text { CLIMATIZACIÓN }(*)\end{array}$} & & \\
\hline & & EXTRAS & $\begin{array}{l}\text { PISCINA(*) } \\
\text { PATIO/JARDINES(*) }\end{array}$ \\
\hline & & \multirow[t]{2}{*}{ LOCALIZACIÓN } & \multirow[t]{2}{*}{ ZONA UBICACIÓN } \\
\hline ECONÓMICAS & PRECIO DE MERCADO & & \\
\hline
\end{tabular}

(*) Variable dicotómica (presencia o ausencia de ese elemento concreto).

No existen fuentes secundarias que proporcionen datos precisos ${ }^{4}$ para el planteamiento de estos modelos econométricos. Por consiguiente, se utilizarán fuentes primarias para confeccionar la base de datos. Se recurrió, en concreto, a las ofertas de vivienda del portal Idealista.com ${ }^{5}$-portal inmobiliario líder en España-, dedicado a la venta y al alquiler de viviendas (nueva y usada / vacacional y habitación), oficinas, locales o naves, garajes y

\footnotetext{
${ }^{4}$ Ahora bien, es cierto que las Sociedades de Tasación o el Ministerio de Fomento proporcionan informaciones referidas al precio, pero concretamente se trata de valores de tasación que no suelen coincidir con los valores de mercado. Además, se trata de valores agregados (no individualizados) y con referencia únicamente a la característica superficie o antigüedad del inmueble que son insuficientes para plantear un modelo.

${ }^{5}$ http://www.idealista.com [43]
} 
terrenos. Se seleccionaron las ofertas ${ }^{6}$ de pisos (libres, usados y ubicados en zonas urbanas) realizadas para la ciudad de Sevilla, durante el primer trimestre de 2013 reuniendo un total de 698 registros.

Para seleccionar las características del inmueble, se efectuó un cuidadoso análisis inicial de los pisos ofertados, de tal modo que en la base de datos solo quedaran recogidas aquellas características que habitualmente fueran mencionadas en las ofertas. Finalmente, se obtuvieron un total de 20 atributos (Tabla 2), 13 de ellos son dicotómicos, es decir, se indica solo la presencia o ausencia en el inmueble de ese elemento (aparecen marcados con un asterisco).

En la Figura 1 se observa claramente que casi la mitad de los pisos de la muestra $(47,6 \%)$ han sido clasificados como "medianos" (con una superficie comprendida entre los 70 y los $115 \mathrm{~m}^{2}$ ). Le siguen en abundancia los pisos pequeños (hasta $70 \mathrm{~m}^{2}$ ), donde se concentra una tercera parte de los inmuebles. Así pues, los pisos catalogados como grandes (entre 115 y hasta $160 \mathrm{~m}^{2}$ ) o muy grandes (más de $160 \mathrm{~m}^{2}$ ) representan tan solo el 12,6\% y el 6,3\% de la muestra, respectivamente.

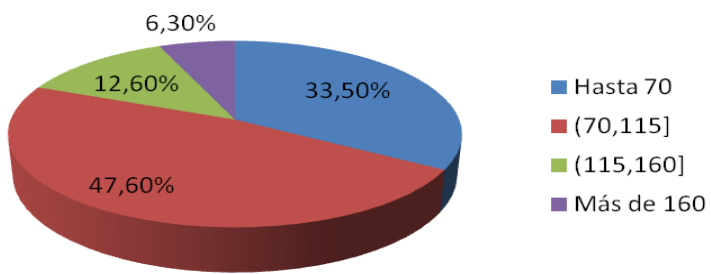

Figura 1. Superficie ( $\mathrm{m} 2$ construidos).

Entre los atributos recogidos en la muestra, pueden distinguirse los que son de carácter cualitativo de las que poseen carácter cuantitativo. Para trabajar con estos últimos, se construyeron índices ${ }^{7}$ que incluyen simultáneamente varios atributos, con objeto de facilitar su inclusión en el modelo y su interpretación económica posterior.

Tabla 3: Indicadores sintéticos aritméticos.

\begin{tabular}{|c|c|}
\hline ÍNDICE & CARACTERÍSTICAS INCLUIDAS \\
\hline $\begin{array}{c}\text { Índice de } \\
\text { APERTURA }\end{array}$ & Presencia de terraza en la vivienda y orientación exterior \\
\hline $\begin{array}{c}\text { Índice de } \\
\text { ANEJOS }\end{array}$ & Cochera y trastero \\
\hline $\begin{array}{c}\text { Índice de } \\
\text { UBICACIÓN }\end{array}$ & Ubicación geográfica y nivel socioeconómico de la misma \\
\hline $\begin{array}{c}\text { Índice de } \\
\text { LUJO }\end{array}$ & Vestidor y chimenea \\
\hline \multirow{2}{*}{$\begin{array}{c}\text { Índice de } \\
\text { SERVICIOS EXTERNOS }\end{array}$} & Jardines y piscina \\
\cline { 2 - 2 } & Jardines, piscina y ascensor \\
\hline \multirow{2}{*}{$\begin{array}{c}\text { Índice de } \\
\text { CONFORT INTERNO }\end{array}$} & Cocina amueblada y armarios empotrados \\
\cline { 2 - 2 } & Cocina amueblada, armarios empotrados y reformas \\
\cline { 2 - 2 } & \\
\hline
\end{tabular}

\footnotetext{
${ }^{6}$ Otros estudios que han utilizado precios de oferta como variable dependiente del modelo de valoración son los de Bover y Velilla (2001) [21] y Bengochea (2003) [44].

${ }^{7}$ Cabe destacar a otros autores que han trabajado con índices en sus propuestas de valoración, tales como Jaén y Molina (1995) [45], Saura (1995) [46], Caridad y Ceular (2001) [38] y Núñez et al. (2013) [47].
} 
En concreto, para este caso se construyeron seis índices cuyos posibles valores se situarán en el intervalo cerrado comprendido entre 0 y 1 . La interpretación es simple: La proximidad a la unidad en su valor indica que las características que componen dicho índice se encuentran en una situación inmejorable y viceversa si el valor estuviera próximo a cero. En la Tabla 3 se especifican los índices construidos y las variables que incluyen cada uno de ellos. Con respecto al índice de ubicación es preciso aclarar que para su elaboración se ha tenido en cuenta la puntuación otorgada a su ubicación dentro de la ciudad (dividiendo previamente la ciudad en cinco áreas), así como el nivel socioeconómico de la misma medido a través de la categoría otorgada por el callejero fiscal.

\subsection{Diseño de Red Neuronal}

El objetivo es encontrar una red neuronal con óptima capacidad de predicción del precio de venta de un inmueble situado en la ciudad de Sevilla. El paquete estadístico empleado fue el Trajan Neural Networks 6.0.

Los detalles de la red seleccionada son los siguientes:

- Tipología: MLP -Multi Layer Perceptron-, puesto que otras variantes proporcionaron resultados pésimos.

- Inputs: Se probaron multitud de combinaciones entre los atributos disponibles. Finalmente fueron seleccionados cuatro: superficie construida, índice de ubicación, índice de anejos y piscina.

- Arquitectura: Tras probar con varias capas ocultas y diferente número de nodos en dichas capas, se eligió un MLP con una única capa oculta que obedece a la estructura: 4:4-8-1:1. En definitiva, el número de inputs asciende a cuatro ${ }^{8}$, existiendo ocho neuronas en la capa oculta y una única neurona en la capa de salida (esta última es el precio total del inmueble).

- Pesos: 40 hasta la capa oculta ${ }^{9}$ y $9^{10}$ hasta la capa de salida, por tanto un total de 49 pesos (9 son umbrales).

- Funciones de activación: Lineal para la capa de entrada, logística para la capa oculta y logística para la capa de salida.

- Función de error: Suma de cuadrados de los errores.

Se dividió la muestra en dos subconjuntos de forma aleatoria con objeto de garantizar la capacidad generalizadora de la red:

- El de entrenamiento, con un total de 558 registros que suponen el $80 \%$ de la muestra.

- El de test, que contiene 140 registros.

Se combinaron dos algoritmos para efectuar el entrenamiento de la red: en una primera fase se usó el algoritmo de retroprogagación de errores -BP o Backpropagation- y en otra posterior se seleccionó el de Gradientes Conjugados $-\mathrm{CG}-$, con las siguientes puntualizaciones:

- Inicialización aleatoria de los pesos y umbrales.

- Máximo número de iteraciones: BP300 CG400.

- $\quad$ Ratio de aprendizaje: 0,01 .

- $\quad$ Término de momento: 0,3.

El resumen de las características de la red seleccionada puede visualizarse en la Tabla 4.

En la Figura 2 se puede apreciar la evolución del error a lo largo del proceso de entrenamiento, con 300 iteraciones en una primera fase mediante algoritmo de Retropropagación de errores. En la segunda fase de entrenamiento se aplica el algoritmo de Gradientes Conjugados, finalizando en la iteración 395, punto en que se alcanza el mínimo error de validación.

\footnotetext{
${ }^{8}$ 4:4 informa de que hay un total de cuatro inputs o neuronas en la capa de entrada y que tras el preprocesamiento de los datos continúa habiendo el mismo número de neuronas en dicha capa, dado que no se han utilizado codificaciones especiales (como el esquema 1-de-N) que impliquen aumentar el número de neuronas para determinadas variables de entrada de carácter cualitativo.

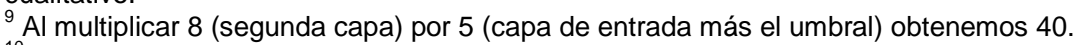

${ }^{10} 8$ neuronas de la segunda capa más el umbral.
} 
Tabla 4: Características de la RNA seleccionada.

\begin{tabular}{|r|c|}
\hline ARQUITECTURA & $4: 4-8-1: 1$ \\
\hline Neuronas en capa entrada & 4 \\
\hline Neuronas ocultas & 8 \\
\hline Neuronas en capa salida & 1 \\
\hline NÚMERO DE PESOS & $49(40+9)$ \\
\hline FUNCIÓN DE ACTIVACIÓN & Lineal-Logística-Logística \\
\hline FUNCIÓN DE ERROR & Suma de Cuadrados de los Errores \\
\hline ALGORITMO DE ENTRENAMIENTO & $\begin{array}{c}\text { Retropropagación de errores (BP) y } \\
\text { Gradientes conjugados(CG) }\end{array}$ \\
\hline
\end{tabular}

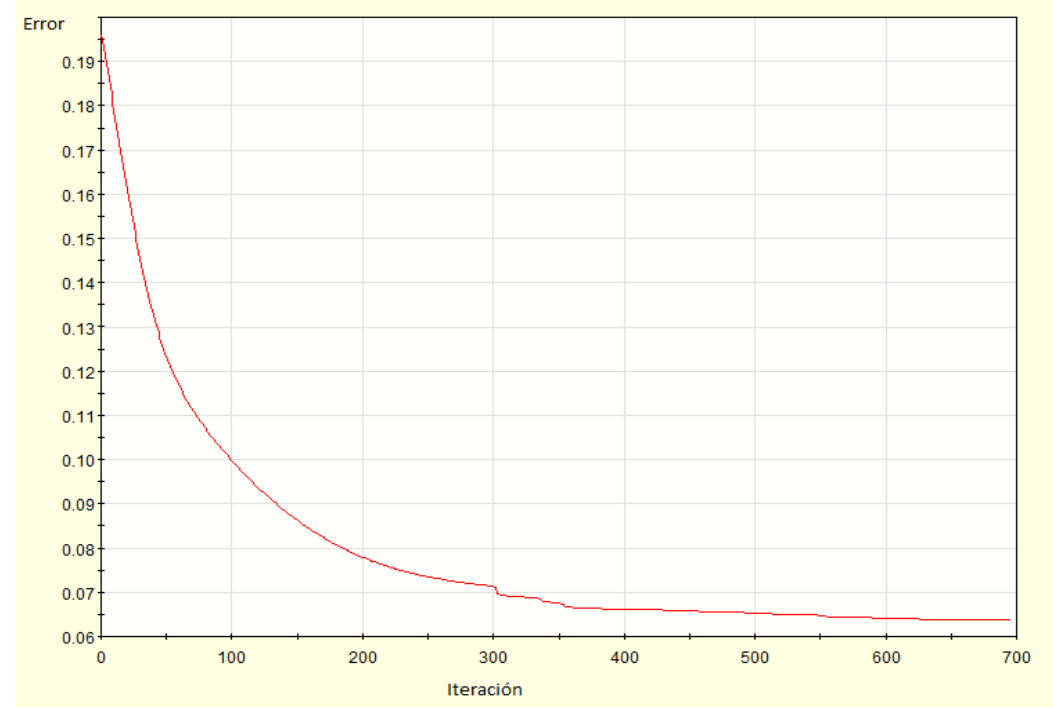

Figura 2. Evolución del error durante el proceso de entrenamiento.

A continuación, se efectúa el análisis de sensibilidad, que permite obtener la influencia que tiene cada uno de los cuatro inputs seleccionados sobre el precio de venta del inmueble. El ratio de error para cada input se obtiene dividiendo el error del modelo sin incluir la variable en cuestión y el error al incluirla. En la Tabla 5 se muestra el ratio obtenido para cada input.

Tabla 5: Análisis de sensibilidad de los inputs de la RNA

\begin{tabular}{|c|c|c|}
\hline INPUT & RATIO & ORDEN \\
\hline SUPERFICIE & 2,173339267 & 1 \\
\hline IUBICACIÓN & 2,015408214 & 2 \\
\hline IANEJOS & 1,037845099 & 3 \\
\hline PISCINA & 1,02490408 & 4 \\
\hline
\end{tabular}

Los resultados ponen de manifiesto que los inputs pueden dividirse en dos grupos atendiendo a su poder explicativo. En el primer grupo se situaría, con un poder explicativo muy elevado, la superficie $(2,1733)$, seguida de cerca del índice de ubicación $(2,0154)^{11}$. En el segundo grupo, con un poder explicativo reducido, se encuentran el índice de anejos $(1,0378)$ y la presencia de piscina $(1,0249)$.

${ }^{11}$ En las pruebas que se ensayaron para determinar la red neuronal idónea, aparecían siempre la superficie y el índice de ubicación como inputs con mayor ratio de sensibilidad. 
Se muestra en la Tabla 6 las matrices de pesos y umbrales relativas a las neuronas entre la capa de entrada y la capa oculta -la notación 2 hace referencia a la capa oculta y aparece seguido de otro número (separado por un punto) que corresponde al número de neurona de dicha capa-. Por otro lado, los pesos correspondientes a las neuronas que conectan la capa oculta con la capa de salida se reflejan en la Tabla 7 -la notación para la neurona de salida es 3.1-.

Tabla 6: Matriz de pesos de neuronas entre capa de entrada y capa oculta.

\begin{tabular}{|c|c|c|c|c|}
\hline & 2.1 & 2.2 & 2.3 & 2.4 \\
\hline UMBRAL & $\begin{array}{c}- \\
1,86211435 \\
\end{array}$ & $\begin{array}{l}0,145509 \\
21\end{array}$ & $\begin{array}{l}0,5429295 \\
\quad 4 \\
\end{array}$ & $\begin{array}{c}1,6797425 \\
5 \\
\end{array}$ \\
\hline SUPERFICIE & $\begin{array}{l}0,849799 \\
38\end{array}$ & 0,54219692 & $\begin{array}{l}4,3434238 \\
9 \\
\end{array}$ & $\begin{array}{c}- \\
6,39145695 \\
\end{array}$ \\
\hline PISCINA & 0,58488553 & $\begin{array}{l}1,453576 \\
62 \\
\end{array}$ & $\begin{array}{c}- \\
2,12937639 \\
\end{array}$ & $\begin{array}{l}0,3850979 \\
5 \\
\end{array}$ \\
\hline IANEJOS & $\begin{array}{l}1,595699 \\
82 \\
\end{array}$ & $\begin{array}{c}- \\
0,28218642 \\
\end{array}$ & $\begin{array}{c}- \\
1,47311447 \\
\end{array}$ & $\begin{array}{l}0,6000569 \\
5 \\
\end{array}$ \\
\hline IUBICACIÓN & $\begin{array}{l}0,698945 \\
02\end{array}$ & $\begin{array}{l}3,264111 \\
51\end{array}$ & $\begin{array}{l}0,3620466 \\
6\end{array}$ & 1,8102938 \\
\hline
\end{tabular}

\begin{tabular}{|c|c|c|c|c|}
\hline & 2.5 & 2.6 & 2.7 & 2.8 \\
\hline UMBRAL & $\begin{array}{c}- \\
0,36842282 \\
\end{array}$ & $\begin{array}{c}- \\
1,87550569 \\
\end{array}$ & $\begin{array}{c}2,3897635 \\
1\end{array}$ & $\begin{array}{c}- \\
0,52347958 \\
\end{array}$ \\
\hline SUPERFICIE & $\begin{array}{c}- \\
5,25211635 \\
\end{array}$ & $\begin{array}{l}0,559320 \\
44 \\
\end{array}$ & $\begin{array}{c}- \\
0,72744911 \\
\end{array}$ & $\begin{array}{l}5,5084905 \\
8 \\
\end{array}$ \\
\hline Piscina & $\begin{array}{l}1,234342 \\
5 \\
\end{array}$ & $\begin{array}{c}- \\
0,42427333 \\
\end{array}$ & 0,23919084 & $\begin{array}{l}0,0591975 \\
3\end{array}$ \\
\hline IANEJOS & $\begin{array}{l}0,468494 \\
49\end{array}$ & $\begin{array}{l}1,701663 \\
94\end{array}$ & $\begin{array}{c}- \\
0,09609738\end{array}$ & 1,6251731 \\
\hline IUBICACIÓN & $\begin{array}{l}3,040611 \\
03\end{array}$ & $\begin{array}{c}- \\
0,73394325\end{array}$ & 3,7441783 & $\begin{array}{l}3,0652370 \\
4\end{array}$ \\
\hline
\end{tabular}

Tabla 7: Matriz de pesos de neuronas entre capa oculta y capa de salida.

\begin{tabular}{|c|c|}
\hline & 3.1 \\
\hline UMBRAL & 2,74763538 \\
\hline $\mathbf{2 . 1}$ & $-0,21574193$ \\
\hline $\mathbf{2 . 2}$ & 2,74402156 \\
\hline $\mathbf{2 . 3}$ & $-3,40255569$ \\
\hline $\mathbf{2 . 4}$ & $-6,2751886$ \\
\hline $\mathbf{2 . 5}$ & $-4,84683044$ \\
\hline $\mathbf{2 . 6}$ & $-0,05247133$ \\
\hline $\mathbf{2 . 7}$ & 5,84738999 \\
\hline $\mathbf{2 . 8}$ & 3,39654348 \\
\hline
\end{tabular}




\subsection{Resultados}

Se procede seguidamente a indicar los estadísticos que han permitido la validación y elección de la red en cuestión. El Coeficiente de Determinación o $\mathrm{R}^{2}$ alcanza un valor de 89,13\%. La media del error en valor absoluto (sin compensaciones entre infravaloraciones y sobrevaloraciones de inmuebles) es de 28.221,97 $€$. El error medio relativo arroja un valor de $16,51 \%$. Además, la correlación existente entre los precios reales y los estimados por la red se sitúa muy próxima a la unidad, con un valor de 0,9443 .

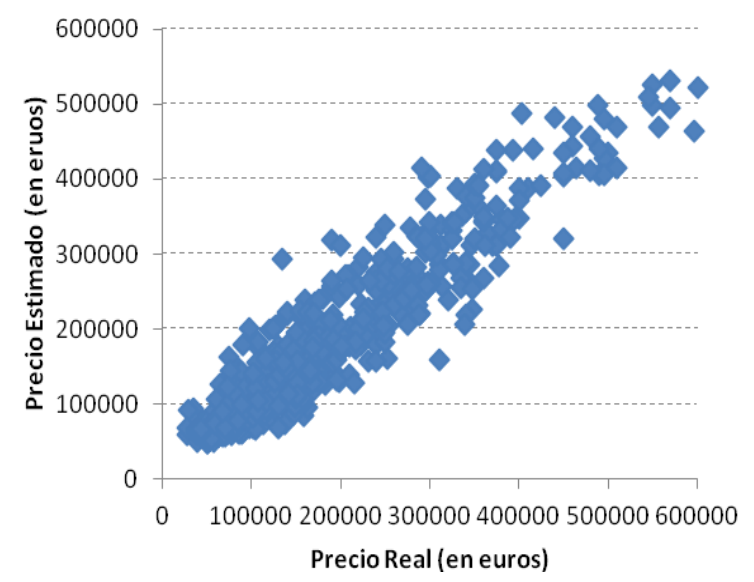

Figura 3. Precio real vs. Precio estimado por la RNA (en euros).

La nube de puntos que refleja la correspondencia entre los precios reales u observados (eje horizontal) y los precios estimados (eje vertical) puede visualizarse en la Figura 3. En términos generales, se observa que los puntos se concentran en torno a la bisectriz del primer cuadrante.

Asimismo, se calculó la ecuación correspondiente a la red estimada. La fórmula de la salida global de la red a la que se pretende llegar es la siguiente:

$$
y_{k}=g\left(a_{k}^{\prime}\right)=g\left(\sum_{j=0}^{m} \omega_{j k}^{\prime} z_{j}\right)=g\left[\sum_{j=0}^{m} \omega_{j k}^{\prime} f\left(\sum_{i=0}^{n} \omega_{i j} x_{i}\right)\right]
$$

A partir de la función de red expresada, las matrices de pesos y umbrales, reflejadas en las Tablas 6 y 7, junto con los factores de cambio de origen y escala (Tabla 8) para la normalización de las variables manejadas, es posible obtener el precio de venta de cualquier inmueble.

Los factores de cambio de origen y escala, tanto de los inputs (variables de entrada) como del output (variable de salida), se muestran en la Tabla 8.

Tabla 8: Factores de preprocesamiento y postprocesamiento de los inputs y output.

\begin{tabular}{|c|c|c|}
\hline & FACTOR DE CAMBIO DE ORIGEN & $\begin{array}{c}\text { FACTOR DE CAMBIO DE } \\
\text { ESCALA }\end{array}$ \\
\hline $\begin{array}{c}\text { SUPERF } \\
\text { ICIE }\end{array}$ & $-0,10204082$ & 0,00408163 \\
\hline PISCINA & $-1,00000000$ & 1,00000000 \\
\hline IANEJOS & 0,00000000 & 1,00000000 \\
\hline $\begin{array}{c}\text { IUBICAC } \\
\text { IÓN }\end{array}$ & 0,00000000 & 1,00000000 \\
\hline PRECIO & $-0,04895105$ & 0,00000175 \\
\hline
\end{tabular}

\subsection{Comparativa RNA vs. MPH}

La Tabla 9 y la Figura 4 permiten una comparación directa en los resultados obtenidos al aplicar las dos metodologías: Método de Precios Hedónicos y Redes Neuronales Artificiales.

El modelo hedónico construido es el siguiente: 


$$
\text { Prêcio }=-136306.0+1942.568 \text { Superficie }+186927.4 \text { IUbicación }+19892.68 \text { IAnejos }+29516.39 \text { Piscina }
$$

Tras efectuar numerosas pruebas se seleccionó una forma funcional lineal, por alcanzar muy buen ajuste. Además, aunque se probó con otras variables explicativas, resultaron determinantes las mismas utilizadas en la RNA, lo que permitirá una posterior comparación entre los precios implícitos de los atributos del inmueble. Inicialmente el modelo presentó heterocedasticidad, que fue corregida por el método propuesto por White (1980) [48]. Puede afirmarse la significación global del modelo a partir del estadístico F-Snedecor ( $F=997.2486$ y pvalor $=0.00$ ) - a un nivel de significación del 5\%-, concluyendo que la forma funcional lineal seleccionada es adecuada. Al realizar el contraste de significación individual t-Student de cada uno de los parámetros del modelo, se observa que todas las variables incluidas en el modelo son significativas. Mediante el índice de condición $\mathrm{K}$ (máx. 13,5), el Factor de Inflación de la Varianza (FIV) (máx. 1,23) y la Tolerancia (de 0,8 en adelante) se determinó que el modelo no presenta multicolinealidad. El test de Chow (Prob F $=0,82$ ) demostró la estabilidad de los parámetros y la U de Theil $(0,148)$ una óptima capacidad predictiva.

Tabla 9: Comparación de los resultados obtenidos con MPH y RNA.

\begin{tabular}{|c|c|c|}
\hline & MPH & RNA \\
\hline $\begin{array}{l}\text { Coeficiente de Determinación } \\
\left(\mathbf{R}^{2}\right)\end{array}$ & $\begin{array}{l}85,27 \\
\%\end{array}$ & $89,13 \%$ \\
\hline Correlación (est. y real) & $\begin{array}{l}0,923 \\
7\end{array}$ & 0,9443 \\
\hline $\begin{array}{l}\text { Raíz del Error Cuadrático } \\
\text { Medio (RECM) }\end{array}$ & $\begin{array}{l}43.86 \\
6,03 \\
\end{array}$ & $37.732,02$ \\
\hline Desviación típica residual & $\begin{array}{l}43.86 \\
6,03\end{array}$ & $37.731,77$ \\
\hline Error medio absoluto (EMA) & $\begin{array}{c}33.20 \\
7,97 \\
\end{array}$ & $\begin{array}{l}28.221,97 \\
349 \\
\end{array}$ \\
\hline Error medio relativo & $\begin{array}{l}0,194 \\
3\end{array}$ & 0.1651 \\
\hline
\end{tabular}

Al examinar la Tabla 9 puede concluirse que las RNA parecen reconocer mejor el proceso de formación de los precios que el modelo hedónico. Se aprecia un incremento en el grado de ajuste del modelo, un aumento en la correlación entre las observaciones y las estimaciones corroborada gráficamente, así como un descenso general de los errores cometidos.

La figura 4 ofrece la nube de puntos correspondientes a los precios reales y los precios estimados, tanto del modelo hedónico como de la red seleccionada. La nube de puntos resultante de ambas metodologías se sitúa muy próxima a la bisectriz del primer cuadrante, surgiendo las diferencias más apreciables para los inmuebles que se sitúan en los extremos: precios muy reducidos o precios muy altos. El modelo hedónico presentó dificultades para predecir los precios de inmuebles con un precio de venta reducido, llegando a predicciones negativas excepcionalmente. Esta disfunción queda corregida por la RNA.

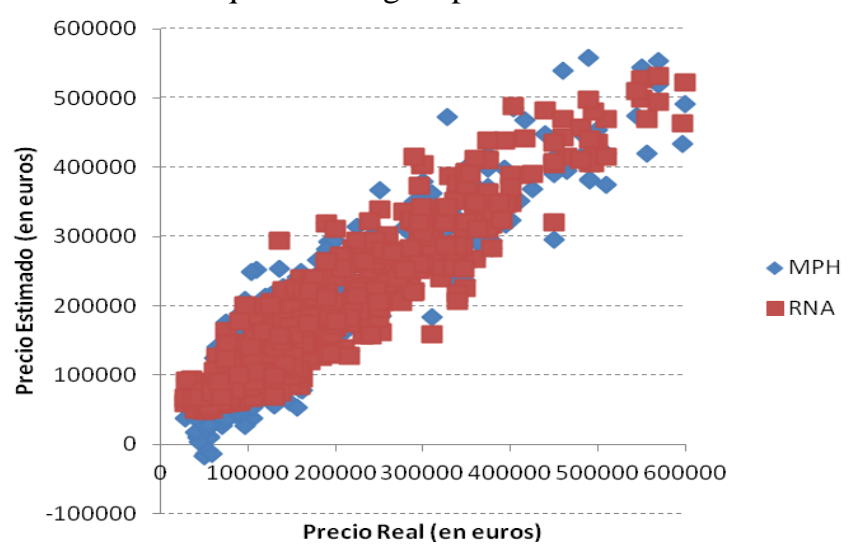

Figura 4. Precio real vs. Precio estimado: Modelo de Precios Hedónicos y Red Neuronal Artificial. 
En términos generales, los errores cuantitativamente mayores se dan, como cabía esperar, para los inmuebles de precio más elevado. No obstante, los errores en los que incurre la red suelen ser menores que los del modelo hedónico. De hecho, al observar la Figura 4, se aprecia claramente que la dispersión de la nube de puntos a partir de los 400.000€ es mayor para el modelo hedónico que para la red. La red tiene tendencia a infravalorar el inmueble en los precios elevados, mientras que el modelo hedónico comete errores mayores tanto por infravaloración como por sobrevaloración.

Solo restaría efectuar el cálculo de los precios implícitos correspondientes a cada uno de los inputs seleccionados en la red. Se determinarán a partir de la ecuación de red obtenida anteriormente, se determina la evolución del precio de la vivienda ante variaciones de cada uno de los inputs por separado, manteniendo todos los demás inputs constantes en sus valores medios.

Seguidamente se analizan, de forma comparada, las figuras que reflejan los precios implícitos correspondientes a la red obtenida y al modelo hedónico.

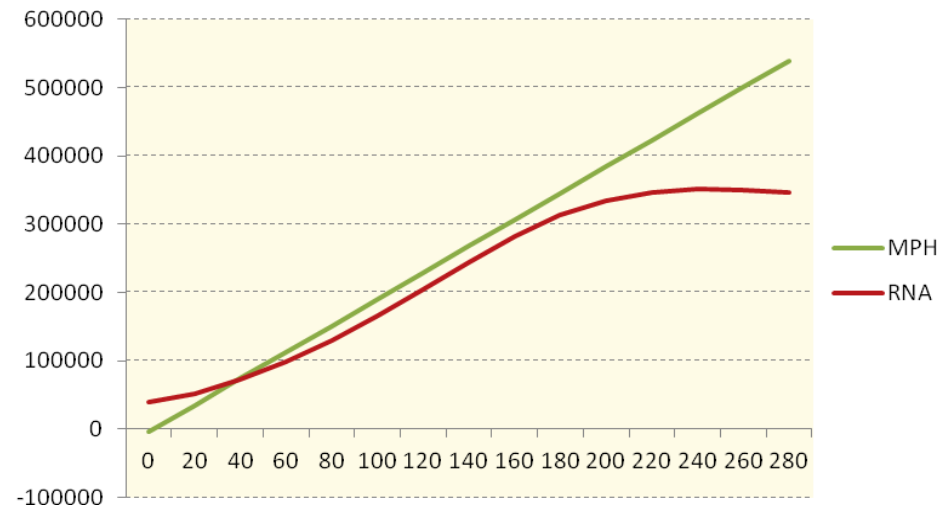

Figura 5. Efecto de la superficie (m2 const.)sobre el precio estimado: MPH vs RNA.

La Figura 5 muestra el incremento marginal del precio de la vivienda conforme se incrementa la superficie de la misma. El modelo hedónico ofrece un incremento lineal creciente que puede concretarse en la cuantía de $38.851,36 €$ en el precio por cada aumento de $20 \mathrm{~m}^{2}$ en la superficie. Por otro lado, los precios marginales ofrecidos por la red adoptan forma de curva, con dos partes diferenciadas: Hasta los $140 \mathrm{~m}^{2}$ tiene una forma ligeramente cóncava (curva de rendimientos crecientes) y llegado a dicho punto de inflexión adopta forma convexa (curva de rendimientos decrecientes) e incluso experimenta una evolución negativa muy leve al final (a partir de los $250 \mathrm{~m}^{2}$ ). Esto significa que el comprador está dispuesto a pagar cada vez más por un incremento determinado en la superficie del inmueble hasta los $140 \mathrm{~m}^{2}$ de superficie, punto a partir del cual el precio marginal del incremento en la superficie disminuirá a medida que aumenta la superficie del inmueble e incluso los incrementos se transforman en ligeros decrementos a partir de los $250 \mathrm{~m}^{2}$.

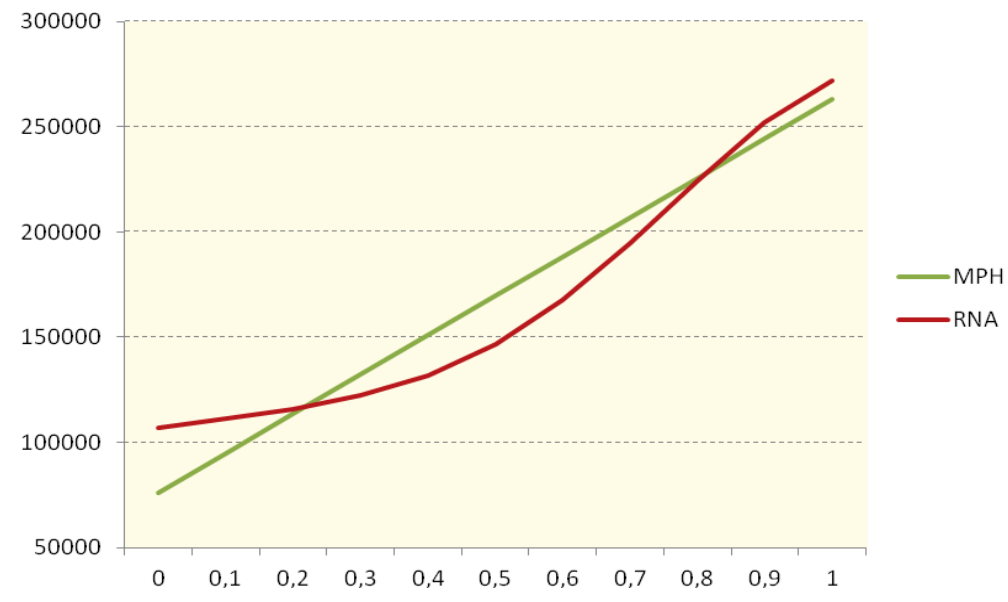

Figura 6. Efecto del índice de ubicación sobre el precio estimado: MPH vs RNA. 
La Figura 6 recoge el efecto que provoca el índice de ubicación sobre el precio de venta estimado del inmueble, aumentando conforme mejora la ubicación geográfica del inmueble, así como el nivel socioeconómico de la zona.

El modelo lineal hedónico indica que el comprador está dispuesto a desembolsar 18.692,74€ por una mejora de 0,1 en el índice de ubicación. Por su parte, la RNA muestra que el incremento que tiene lugar en el precio difiere dependiendo del nivel del índice. Así pues, la red adopta una curva de rendimientos crecientes (cóncava), con ligeros incrementos en los niveles más bajos del índice. A partir de 0,5 los incrementos son muchos más elevados (entre 14.754 y 29.764) y es en 0,8 donde se alcanza un punto de inflexión que provoca que los incrementos se tornen decrecientes hasta llegar al índice de 1. Dicho de otro modo, al final la curva se torna a convexa. En principio, parece lógico pensar que el comprador esté dispuesto a pagar un precio implícito menor al pasar de una pésima ubicación a una ubicación mediocre, que al pasar de una ubicación mediocre a una buena ubicación.

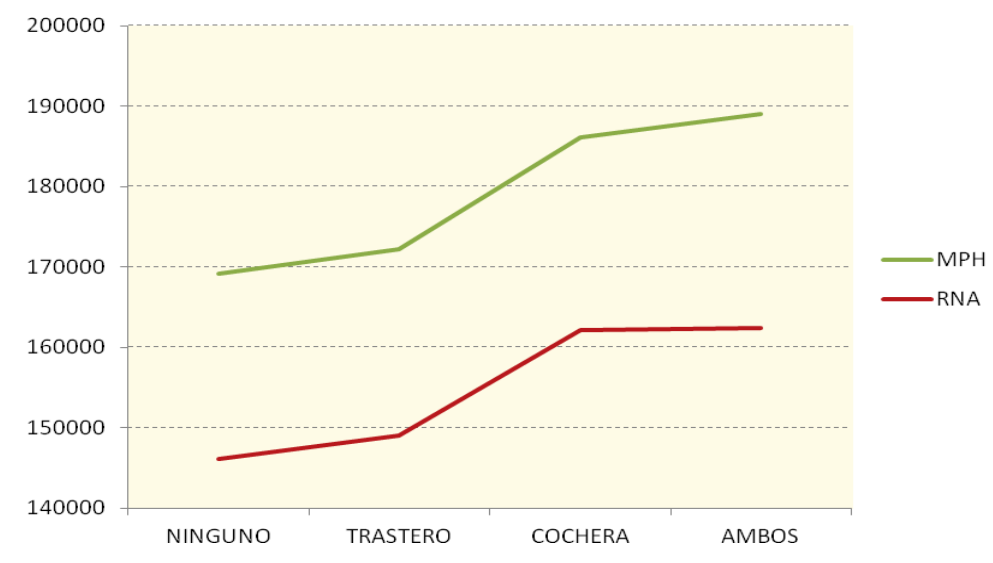

Figura 7. Efecto del índice de anejos sobre el precio estimado: MPH vs RNA.

Respecto al precio implícito de los anejos a la vivienda - garaje y trastero- hay que destacar que ambas metodologías ofrecen un precio implícito similar para el trastero (ver Figura 7), que queda cifrado en 2.983,90€ por el modelo hedónico y en $2.865,04 €$ por la red. También quedan muy cercanos los precios implícitos ofrecidos para la cochera: $16.908,78 €$ el hedónico frente a 16.054,64€ de la red. Sin embargo, en el modelo hedónico el precio implícito de ambos elementos sería la suma de los mismos -19.892,68€-, mientras que la red modera el precio del conjunto cifrándolo en $16.293,85 €$.

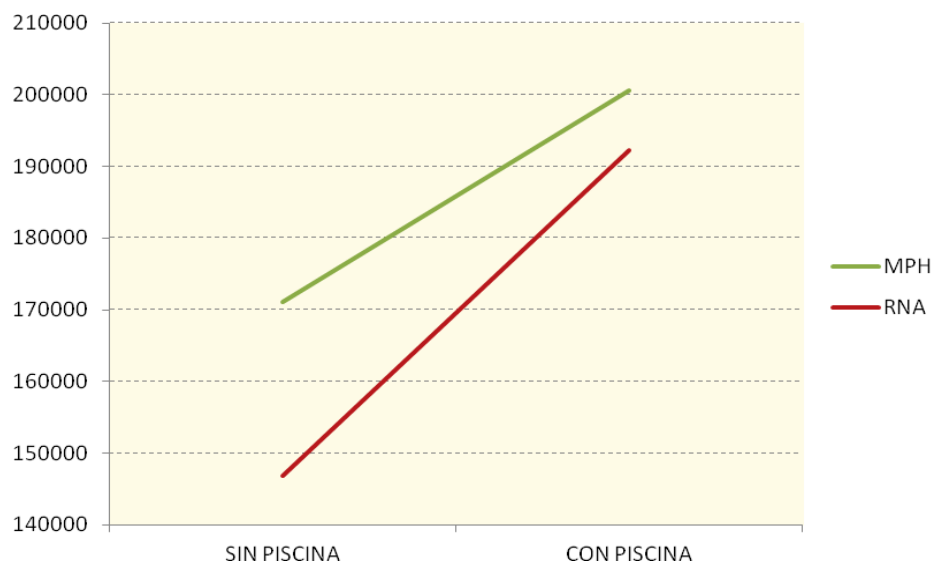

Figura 8. Efecto de la piscina sobre el precio estimado: MPH vs RNA.

Por último, se analiza el efecto del precio implícito correspondiente a la piscina en el precio de venta del inmueble (Figura 8). Según el modelo hedónico el comprador estaría dispuesto a desembolsar 29.516,39€ más si el inmueble cuenta con piscina, mientras que la red cifra la presencia de dicho elemento en 45.483,54€. En principio, pueden parecer algo elevados estos precios pero hay que tener en cuenta que la presencia de piscina lleva normalmente aparejados otros elementos que elevan considerablemente el precio del inmueble, tales como jardines, pistas deportivas o zonas de recreo infantil. 


\section{Conclusiones}

La complejidad del mercado inmobiliario ha favorecido la aparición y el desarrollo de metodologías alternativas a las que tradicionalmente han sido utilizadas en la valoración de inmuebles.

Con el objetivo de construir modelos econométricos para determinar de forma objetiva el precio de mercado de una vivienda en la ciudad de Sevilla -partiendo de sus múltiples y variados atributos- han sido usadas la metodología hedónica clásica y las RNA. Los resultados obtenidos muestran que las características que más influyen en la determinación del precio de la vivienda son: la superficie construida $\left(\mathrm{m}^{2}\right)$, la ubicación -definida mediante la confección de un índice que pondera la situación geográfica del inmueble junto con el nivel socioeconómico de la zona-, el garaje y el trastero -incidencia calculada también a través de un índice-y la presencia de piscina. La variable superficie suele ser la nota común en los modelos de valoración inmobiliaria. Esta variable exógena es capaz de explicar más del $60 \%$ de la varianza de los valores de mercado de las viviendas analizadas. Lógicamente en una ciudad tan heterogénea como Sevilla era imprescindible incluir en la ecuación una referencia a la ubicación geográfica del inmueble. Por otro lado, la presencia de elementos anejos (cochera y trastero), que van incluidos en el precio de venta, hacen aumentar de forma significativa el mismo. Asimismo, también destacó la presencia de piscina entre los atributos externos del inmueble.

Los resultados obtenidos ponen en evidencia la superioridad de las RNA frente a los clásicos modelos hedónicos. Se aprecia un mayor grado de ajuste del modelo, un incremento en la correlación entre las observaciones y las estimaciones, así como un descenso general de los errores cometidos. No obstante, hay que tener presente que la red también incurre puntualmente en errores, sobre todo en aquellos inmuebles que presenten un precio real de venta muy reducido o, por el contrario, muy elevado.

Asimismo, dentro del ámbito de valoración en el mercado inmobiliario, varios estudios han efectuado comparaciones entre la regresión múltiple y los sistemas de inteligencia artificial (Tay y Ho, 1992 [37]; Do y Grudnitski, 1993 [49]; Kauko, 2003 [32]; Peterson y Flanagan, 2009 [50]), mostrándose la superioridad de éstas en la mayoría de los casos por dos evidencias fundamentales mostradas en el presente estudio: Mayor precisión y mayor capacidad para estimar el valor de las propiedades especiales (outliers). Sin embargo, en diversos ámbitos del conocimiento se han realizado estudios comparados de técnicas estadísticas tradicionales y modelos neuronales llegándose a la conclusión de que no se puede afirmar con rotundidad que las redes neuronales sobrepasen siempre en eficiencia a las técnicas estadísticas tradicionales y lo apropiado es aplicar en cada caso concreto la solución más idónea.

\section{Referencias}

[1] M. P. García Almirall. Introducción a la valoración inmobiliaria. Research Paper. Centre de Política de Sòl i Valoracions. Càtedra d'Arquitectura Legal, Dret Urbanístic i Valoracions, Escola Tècnica Superior d'Arquitectura de Barcelona, UPC. Barcelona, 2007.

[2] E. Ballestero y J. A. Rodríguez. El precio de los inmuebles urbanos, Cie. Inversiones Editoriales Dossat 2000. Madrid, 1999.

[3] A. Llano Elcid. Valoraciones inmobiliarias. Fundamentos teóricos y manual práctico. Ediciones inmobiliarias Llano. Bilbao, 2007.

[4] Banco de España, Boletín económico, julio-agosto 2014. Las sociedades de tasación. Actividad y resultados en 2013. Madrid, 2014.

[5] E. Pagourtzi, E., V. Assimakopoulos, T. Hatzichristos y N. French. Real estate appraisal: a review of valuation methods, Journal of Property Investment \& Finance, 21(4), 383-401, 2003. doi: http://dx.doi.org/10.1108/14635780310483656

[6] J. Gallego Mora-Esperanza. La inteligencia artificial aplicada a la valoración de inmuebles. Un ejemplo para valorar Madrid, CT: Catastro no 50, Abril: 51-67, 2004.

[7] J. Aznar Bellver, J., F. Guijarro Martínez, A. E. López Perales y R. González Mora: Valoración inmobiliaria. Métodos y aplicaciones (España e Iberoamérica), Editorial Universitat Politècnica de València. Valencia, 2012.

[8] J. V. Ferrando Corell. Valoración de inmuebles de naturaleza urbana. Servicio de publicaciones de la Universidad Politécnica de Valencia, 2011.

[9] E. Figueroa y G. Lever. Determinantes del precio de la vivienda en Santiago: Una estimación hedónica, Estudios de Economía, 19 (1), 67-84, 1992.

[10] A.C. Goodman. A dynamic equilibrium model of housing demand and mobility with transations costs, Journal of Housing Economics, 4, 307-327, 1995. doi: http://dx.doi.org/10.1006.jhec.1995.1015 
[11] A. T. Court. Hedonic Price Indexes with Automotive Examples, Dinamics of Automovile Demand. General Motors Corporation: 99-117, 1939.

[12] P. F. Colwell y G. Dilmore. Who Was First? An Examination of an Early Hedonic Study, Land Economics, 75 (4), 620-626, 1999. doi: http://dx.doi.org/10.2307/3147070

[13] G. C. Haas. A Statistical Analysis of Farm Sales in Blue Earth County, Minnesota, As a Basis for Farmland Appraisal. Masters Thesis, the University of Minnesota, 1922.

[14] R. Ridker y A. Henning. The determinants housing prices and the demand for clean air, Journal Environmental Economy Management, 5, 81-102, 1967.

[15] Z. Griliches. Introduction: Hedonic Price Indexes Revisited. In Price Indexes and Quality Changes: Studies in New Methods of Measurement. Cambridge. Harvard University Press, 3-15, 1971.

[16] S. Rosen. Hedonic Prices and Implicit Markets: Product Differentiation in Pure competition. Journal of Polical Economy, 82, 34-55, 1974. doi: http://dx.doi.org/10.1086/260169

[17] A. M. Freeman. Hedonic price, property values and measuring environmental benefits: a survey of the issues. Scandinavian Journal of Economics, 81, 154-173, 1979. doi: http://dx.doi.org/10.2307/3439957

[18] G. S. Sirmans, G.S.; D. A. MacPherson y E. N. Zietz. The composition of hedonic pricing models, Journal of Real Estate Literature, 13(1), 3-43, 2005.

[19] D. Peña y J. Ruiz-Castillo. Robust methods of building regression models. An application to the housing sector. Journal of Business and Economic Statistics, 2, 10-20. (Existe una versión española en Estadística Española, 97. 47-76, 1984. doi: http://dx.doi.org/10.1080/07350015.1984.10509366

[20] P. Brañas y J. M. Caridad. Demanda de características de la vivienda en Córdoba: un modelo de precios hedónico, Revista de Estudios Regionales, 46, 139-153, 1996.

[21] C. Bilbao Terol. Relación entre el precio de venta de una vivienda y sus características: Un análisis empírico para Asturias, Revista Asturiana de Economía, 18, 141-150, 2000.

[22] O. Bover y P. Velilla. Precios hedónicos de la vivienda sin características: el caso de las promociones de viviendas nuevas. Estudios Económicos, 73. Banco de España. Madrid, 2001.

[23] A. García Pozo. Una aproximación a la aplicación de la metodología hedónica: especial referencia al caso del mercado de la vivienda, Cuadernos de CC.EE. y EE., 53, 53-81, 2007.

[24] J. M. Fitch Osuna y P. García Almirall. La incidencia de las externalidades ambientales en la formación espacial de valores inmobiliarios: el caso de la región metropolitana de Barcelona, ACE, 6, 673-693, 2008.

[25] C. Chasco, C. y J. Le Gallo. The impact of objective and subjective measures of air quality and noise on house prices: A multilevel approach for downtown Madrid, Economic Geography, 89 (2), 127-148, 2013. doi: http://dx.doi.org/10.1111/j.1944-8287.2012.01172.x

[26] B. Martín Del Brío y A. Sanz Molina. Redes Neuronales y Sistemas Borrosos. Ed. Ra - Ma. Madrid, 2006.

[27] P. Isasi Viñuela y I. M. Galván León. Redes neuronales artificiales: Un enfoque práctico. Ed. Pearson Educación. Madrid, 2004.

[28] E. N. Sánchez Camperos y A. Y. Alanís García. Redes neuronales: Conceptos fundamentales y aplicaciones a control automático. Pearson-Prentice Hall. Madrid, 2006.

[29] S. Haykin. Neural networks: A comprehensive foundation. Prentice -Hall. $2^{\text {nd }}$ Edition, 1999.

[30] W. S. McCulloch y W. Pitts. A logical calculus of the ideas immanent in nervous activity, Bulletin of Mathematical Biophysics 5, 115-133, 1943. doi: http://dx.doi.org/10.1007/BF02478259

[31] F. Rosenblatt. The Perceptron: A theory of statistical separability in cognitive systems. Technical Report VG1196-G-1, Cornell Aeronautical Laboratory, 1958.

[32] D. Rumelhart, G. Hinton y R. Williams. Parallel distributed Processing, chapter Learning representations by back-propagating errors. MIT Press, 1986.

[33] N. García Rubio. Desarrollo y aplicación de redes neuronales artificiales al mercado inmobiliario: aplicación a la ciudad de Albacete. Tesis Doctoral. Universidad de Castilla - La Mancha, 2004.

[34] T. Kauko. On current neural network applications involving spatial modelling of property prices, Journal of Housing and the Built Environment, 18 (2), 159-181, 2003. doi: http://dx.doi.org/10.1023/A:1023977111302

[35] V. Kontrimas y A. Verikas. The mass appraisal of the real estate by computational intelligence, Applied Soft Computing, 11(1), 443-448, 2011. doi: http://dx.doi.org/10.1016/j.asoc.2009.12.003 
[36] E. Soria y A. Blanco. Redes neuronales artificiales. ACTA (Autores científico-técnicos y académicos). Id. $19,25-33,2001$.

[37] J. Gallego Mora-Esperanza. Modelos de valoración automatizada, CT: Catastro nº 62, Abril, 7-26, 2008.

[38] R. Borst. Artificial Neural Networks: The Next Modelling/ Calibration Technology for the Assessment Community? Property Tax Journal, IAAO, 10 (1), 69 - 94, 1991.

[39] D. P. Tay y D. K. Ho: Artificial intelligence and the mass appraisal of residential apartment, Journal of Property Valuation \& Investment, 10, 525 - 540, 1992. doi: http://dx.doi.org/10.1108/14635789210031181

[40] J. M. Caridad y N. Ceular: Un análisis del mercado de la vivienda a través de redes neuronales artificiales, Estudios de Economía Aplicada, 18, 67-81, 2001.

[41] J. Lara Cabeza. Aplicación de las redes neuronales artificiales al campo de la valoración inmobiliaria, Mapping, 104, 64-71, 2005.

[42] M. Landajo, A. Bilbao-Terol y C. Bilbao-Terol. Nonparametric neural network modeling of Hedonic Prices in the housing market, Empirical Economics, 42 (3), 987-1009, 2012. doi: http://dx.doi.org/10.1007/s00181011-0485-9

[43] Portal Inmobiliario IDEALISTA.COM: http://www.idealista.com

[44] A. Bengochea Morancho. A hedonic valuation of urban green areas, Landscape and Urban Planning, 66, 3541, 2003. doi: http://dx.doi.org/10.1016/S0169-2046(03)00093-8

[45] M. Jaén y A. Molina. Modelos econométricos de tenencia y demanda de vivienda. Servicio de publicaciones de la Universidad de Almería, 1995.

[46] P. Saura. Demanda de características de la vivienda en Murcia. Secretariado de Publicaciones de la Universidad de Murcia, 1995.

[47] J. Núñez Tabales, J. M. Caridad Ocerin y F. J. Rey Carmona. Artificial Neural Networks for predicting real estate prices, Revista de Métodos Cuantitativos para la Economía y la Empresa, 15, 3-28, 2013.

[48] H. White. A heterokedasticity-consistent a variance matrix estimator and a direct test for heterokedasticity, Econometrica, 48, (4), 817-827, 1980. doi: http://dx.doi.org/10.2307/1912934

[49] A. Do y G. Grudnitski. A Neural Network Analysis of the effect of age on housing values, The Journal of Real Estate Research, Vol. 8 (2), 253-264, 1993.

[50] S. Peterson y A. Flanagan. Neural Network Hedonic Pricing Models in Mass Real Estate Appraisal, Journal of Real Estate Research, 31, n² 2, 147-164, 2009. 